\title{
Degradation of Azodyes in Wastewater by Using Hydrodynamic Cavitation Technique
}

\author{
G. Gayathri, Dinesh Sankar Reddy, C.R. Shashi Kiran, \\ P. Maveen Kumar Reddy, Beulah
}

\begin{abstract}
The organic waste water discharged from various industries consists of large amounts of dyes \& cyanides \& other toxic carcinogenic pollutants which are harmful to human health \& ecosystem. Release of carcinogenic dyes is hazardous \& has a detrimental effect on the well being of an individual. The present work is focussed at finding the viability of hydrodynamic cavitations process in the degradation of dyes. To study the degradation, influence of various parameters on degradation rate has been studied.
\end{abstract}

Keywords--- Dyes, Waste Water, Hydrodynamic Cavitation, Degradation Rate.

\section{INTRODUCTION}

The waste water released from communities, industries, hospitals etc is a mixture of several organic \& inorganic matter. It contains certain amount of hazardous matter \& when it is disposed to water bodies, some pollutants may get dissolved; some may float in water or get deposited on bed. This results in the water pollution by which the quality of the water gets depleted affecting the aquatic life. These pollutants can also penetrate through the soil pores \& affect the groundwater. The water is majorly polluted by industrial wastes such as textile, paper, pesticides and many more. When discharged into the water bodies, it devastates the self purification phenomena of the water bodies which reduces the ability of recovery. This attributes to deep-rooted effects on human being, aquatic life \& surroundings.

The textile industry is one of the most prominent industry which accounts for $54 \%$ release ofdye effluent. The dyeing industry releases $21 \%$, paper and pulp industry $10 \%$, tannery and paint industry $8 \%$ and the colour fabricating industry $7 \%$ and are identified to produce huge quantities of dye effluents from few related processes $[1,2]$. Dye effluents can endanger the lives of creatures and people [3, 4]. A perfect dye removal method is mandatorily required which has the capacity to productively expel huge amounts of dye from wastewater in a short span without delivering auxiliary contamination [5].

Present study is mainly focused on Advanced Oxidation Process (AOP) as an efficient chemical treatment method for dye degradation. In addition, AOP has been beneficial in the perspective of economy and dye removal efficiency. Since two decades, number of research works are in progress for

G. Gayathri, Department of Chemical Engineering, Jawaharlal Nehru Technological University, Anantapur, India. (e-mail: gayathri.jayaram30@gmail.com)

Dinesh Sankar Reddy, Department of Chemical Engineering, pdsreddy@gmail.com)

C.R. Shashi Kiran, Department of Civil Engineering, Rashtreeya Vidyalaya College of Engineering, Bengaluru, India. (e-mail: shashimar8@gmail.com)

P. Maveen Kumar Reddy, M.Tech (Environmental Engineering), Jawaharlal Nehru Technological University, Anantapur, India. (e-mail: Mkr.mvr.p@gmail.com)

M. Beulah, Department of Civil Engineering, CHRIST (Deemed to be University), India. (e-mail: Beaulah.y@gmail.com)
Manuscript received September 16, 2019. Jawaharlal Nehru Technological University, Anantapur, India.(e-mail:

innovation and improving the technologies especially in the region of advanced oxidation for the Dye toxin degradation. Among all AOP methods, cavitation is the best process to treat colored wastewater in extremely effective and economical way. [30, 31]

Degradation of dyes by Hydrodynamic cavitation (HC) is a very efficient $\&$ economical technique, which depends on geometrical arrangement of orifice plate; cavitation number (CV) and various other parameters namely initial concentration, $\mathrm{pH}$, temperature, and inlet pressure. Effects of few parameters on dye degradation are further stated. Initial concentration is one of the affecting factors in degradation of dyes; different authors have discerned the impact of concentration with different perception. Few authors have estimated the impact of initial concentration on the rate of pollutant degradation, while others have considered the impact of focus on the percent decrease of contamination level in aqueous effluent [6]. The rate of hydroxyl $\left(\mathrm{OH}^{*}\right)$ radicals utilization will be the greatest as contrasted with low concentration of pollutant. Hence the degradation rate would be large but the percentage drop might be lesser due to higher loading rate. The rate of degradation AR88 dye increases with increasing concentration of sample and it is

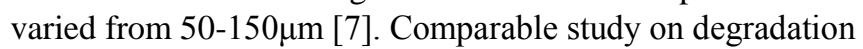
efficiencies of Rhodamine-B and K-2BP was observed with the help of HC by varying the initial concentration of dye. It was interposed that on increase in the initial concentration from 10 - $50 \mathrm{ppm}$, the degradation decreased from $92 \%$ $24.7 \%[8,9]$.

The $\mathrm{pH}$ of solution is also one of the important factor to paramount the degradation rates of dye, which is dependent on the nature and state of pollutant i.e., ionic or molecular form, hydrophobic in nature when it is in molecular state [10]. Apart from the effect of $\mathrm{pH}$, nature and the state of pollutant molecules, few authors have reported that the reactivity and generation of $\mathrm{OH}$ radicals can also be affected by altering the solution $\mathrm{pH}$. The degradation efficiency is increased with decreasing $\mathrm{pH}$ value of sample from 11-2 [7, $11,12-16]$, the particles of dye turns out to be more hydrophobic in nature at sub-atomic state. In the favourable acidic condition, slower recombination of generated $\mathrm{OH}^{*}$ radicals also resist the scavenging of released $\mathrm{OH}^{*}$ radicals by other ionic spices present in the solution such as $\mathrm{HCO} 3-$ and $\mathrm{CO} 32-[7,16]$, where as in basic medium, the dye particles gets ionized and become hydrophilic in nature and subsequently stay in the bulk fluid. Only $10 \%$ of created $\mathrm{OH}^{*}$ radicals are diffused into bulk solution because of the $\mathrm{OH}^{*}$ radicals recombination [6].The temperature of solution is also one of the crucial factors in cavitational yield and degradation efficiency. Different wastewater samples require different optimum temperature to degrade the dye.

Published By: 


\section{DEGRADATION OF AZODYES IN WASTEWATER BY USING HYDRODYNAMIC CAVITATION TECHNIQUE}

High operating temperature may be functional because the number of cavities formed may be large due to the higher rate of transformation of liquid into vaporous cavities. Few authors reported that, the degradation of Rhodamine-B, Chitosan, etc. requires temperature range 300c $-700 \mathrm{c}$ and then decreases because of choked cavitation [7, 17, 18]. Few other studies have reported that low temperature is also favourable to degrade the dye; the $90 \%$ degradation of carbamazepine is observed at low temperature of $250^{\circ} \mathrm{c}$, with further increase in temperature the efficiency decreased [19], which means the temperature depends on the liquid vapour pressure. With increase of temperature, the vapour pressure also increases and thus cavities are formed at low operating pressure and at high temperature [6]. Among all studies, it is concluded that the moderate temperature should be within the range of $250^{\circ} \mathrm{c}-500^{\circ} \mathrm{c} \&$ is well suited for wastewater treatment.

\section{MATERIALS AND METHODS}

\section{Materials}

1. Methyl blue dye (powder form) molecular weight and formula : $\quad 799.95 \quad \mathrm{~g} / \mathrm{mol}$ and C37H27N3Na2O9S3.

2. Hydrogen peroxide $\left(\mathrm{H}_{2} \mathrm{O}_{2}\right)$

3. Orifice plates made with stainless steel with 8 number holes of $2 \mathrm{~mm}$ diameter of circular and hexagonal geometry.

\section{Advanced Oxidation Process (AOP)}

The generation and utilisation of hydroxyl free radicals $\left(\mathrm{OH}^{*}\right)$ are involved with Advanced oxidation process. As a strong oxidant, the $\mathrm{OH}^{*}$ free radicals that develops in the oxidation process are used to demolish compounds that cannot be oxidized by regular oxidants such as ozone, chlorine and oxygen. The belowfigure describes the methodology of Advanced oxidation process with oxidizingagent $\left(\mathrm{H}_{2} \mathrm{O}_{2}\right)$.

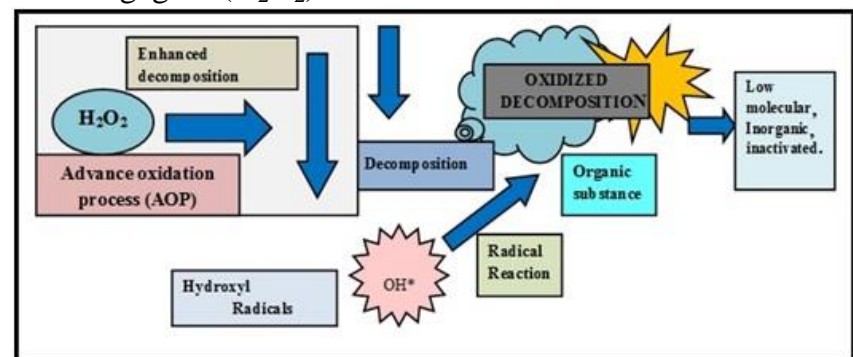

Fig.1: Methodology of advanced oxidation process with oxidizing agent

There are various dye degradation techniques like Cavitations (acoustic and hydrodynamic) [20, 21], photocatalytic oxidation [22], Fenton chemistry [23], Chemical oxidation [24]. Among all AOP techniques, treatment of wastewater by cavitations is one of the finest alternative techniques $[7,30]$.

\section{Cavitation}

Cavitation is defined as the formation and growth of cavities at low pressure region (i.e. region below vapour pressure) which is followed by collapse of cavities at high pressure region extremely within small interval of time (milliseconds) and the collapse of bubbles gives rise to confined "hot spots", with transient temperature and pressures [24]. Under such conditions, the water molecules separate into $\mathrm{H}^{*}$ and $\mathrm{OH}^{*}$ free radicals. The radicals released from the cavitation energy are diffused into liquid medium. Among the diffused radicals, only $\mathrm{OH}^{*}$ radicals reacts with organic pollutants and oxidize them [3, 44]. Cavitation involves two mechanisms in the organic pollutants destruction. They are i)Reaction of pollutants with $\mathrm{OH}^{*}$ radicals $[25,26,30,31]$ \& ii) Thermal decomposition [27, 28]. The classification of cavitation is based on method of generation of cavities namely, acoustic, optic, hydrodynamic and particle cavitation. Among all these techniques, the method of hydrodynamic cavitation is more efficient and economical to degrade the pollutants \& the present study aims in degradation efficiency $\&$ rates.

\section{Hydrodynamic Cavitation}

In $\mathrm{HC}$, the cavitation is produced by the liquid that passes through the constriction of orifice be in control of inlet pressure. The velocity of liquid increases at the low pressure when liquid passes through orifice. At critical point of section i.e. at low pressure, the liquid generates large amount of cavities and these cavities collapses with high intensity when they reach downstream section as shown in figure

\section{Experimental and Analytical Method}

Hydrodynamic cavitation based dye degradation has been carried out at different conditions using 30 litres dye wastewater for a constant circulation time of 60 minutes. The usual concentration of the dye in the practical industrial wastewater is found to be in the range of $10-150 \mathrm{mg} / \mathrm{lit}[29$, 30]. Hence an initial concentration of Methyl blue was kept constant for all the cases at $40 \mathrm{mg} / \mathrm{lit}$ to establish the kinetics at a room temperature.

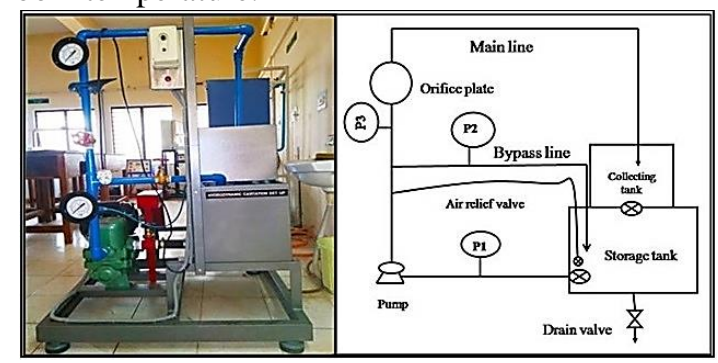

Fig. 2: Hydrodynamic cavitation setup and line diagram

Initially the required amount of dye in the powderform is weighed and mixed thoroughly with wastewater in storage tank. When operating the pump, a constant inlet pressure is maintained by controlling the pressure valve on bypass line. The experiment is conducted at an optimum inlet pressure for good dye degradation.

The pump imbibes the wastewater containing methyl blue dye from the storage tank at constant flow rate. The water flows through the orifice plate ( 8 number of holes circular or hexagonal orifice plate) present on the main line and gets treated. Finally treated water is collected from the collecting tank (fixed at the top of the rectangular tank) with respect to the time. 
UV-Spectrophotometer (Model: Shimadzu1800) is used to assess the degradation of Methyl blue and to calculate the concentration of dye by analyzing the absorbance at the wavelength of $308 \mathrm{~nm}$ for dye solution.

\section{RESULTS AND DISCUSSIONS}

The experimental results with respect to degradation of Methyl blue using hydrodynamic cavitation method with and without the presence of $\mathrm{H}_{2} \mathrm{O}_{2}$ are presented \& dispensed. The orifice geometry effect on the amount of dye degradation is also accorded.

\section{Hydraulic Characteristics}

Cavitation number $(\mathrm{Cv})$ is a dimensionless parameter used to investigate the intensity of $\mathrm{HC}$ inside the cavitation device (Orifice).

The hydraulic characteristics of Cavitating device has been studied by using both the $\mathrm{Cv}$ and the flow rate in mainline. The correlation between $\mathrm{Cv}$ and the pressure and flow rate is given by the following equation:

$$
\mathrm{CV}=\frac{\mathrm{P}_{2}-\mathrm{P}_{\mathrm{V}}}{1 / 2\left(\rho \mathrm{Oo}^{2}\right)}
$$

In the above equation, $\mathrm{P}_{2}$ is the fully recovered downstream pressure, $\mathrm{P}_{\mathrm{v}}$ is the vapor pressure of liquid and $\mathrm{V}_{0}$ is the liquid velocity at the orifice.

Liquid velocity can be estimated by knowing the flow rate through the mainline.The following table provides the data connecting the flow rate and cavitation numbers at different inlet pressures.

Table 1: Cavitation number calculations for orifice plate with 8 no. of circular holes

\begin{tabular}{|c|c|c|c|c|c|}
\hline $\begin{array}{c}\text { Pressu } \\
\text { re } \\
\text { (bars) }\end{array}$ & $\begin{array}{c}\text { Volume } \\
\text { Collecte } \\
\mathbf{d} \\
\mathbf{( m 3 )}\end{array}$ & $\begin{array}{c}\text { Time } \\
\text { taken } \\
\text { for } \\
\text { collecti } \\
\text { on (s) }\end{array}$ & $\begin{array}{c}\text { Flow } \\
\text { rate } \\
(\mathbf{m} 3 / \mathbf{s}) \\
(\mathbf{Q})\end{array}$ & $\begin{array}{c}\text { Velocity } \\
\text { at } \\
\text { Orifice(V } \\
\mathbf{o})(\mathbf{m} / \mathbf{s})\end{array}$ & $\mathbf{C v}$ \\
\hline 0.5 & $\begin{array}{c}0.01153 \\
75\end{array}$ & 45.20 & $\begin{array}{c}2.55 \times 1 \\
0-4\end{array}$ & 81.23 & $\begin{array}{c}1.88 \\
1\end{array}$ \\
\hline 1.5 & $\begin{array}{c}0.01153 \\
75\end{array}$ & 35.93 & $\begin{array}{c}3.21 \times 1 \\
0-4\end{array}$ & 102.21 & $\begin{array}{c}1.18 \\
9\end{array}$ \\
\hline 2.5 & $\begin{array}{c}0.01153 \\
75\end{array}$ & 30.5 & $\begin{array}{c}3.78 \times 1 \\
0-4\end{array}$ & 120.41 & $\begin{array}{c}0.85 \\
7\end{array}$ \\
\hline 3.5 & $\begin{array}{c}0.01153 \\
75\end{array}$ & 25.92 & $\begin{array}{c}4.45 \times 1 \\
0-4\end{array}$ & 141.77 & $\begin{array}{c}0.61 \\
8\end{array}$ \\
\hline 4.5 & $\begin{array}{c}0.01153 \\
75\end{array}$ & 21.20 & $\begin{array}{c}5.44 \times 1 \\
0-4\end{array}$ & 173.22 & $\begin{array}{c}0.41 \\
4\end{array}$ \\
\hline 5.5 & $\begin{array}{c}0.01153 \\
75\end{array}$ & 19.22 & $\begin{array}{c}6.02 \times 1 \\
0-4\end{array}$ & 191.28 & 0.33 \\
\hline 6.5 & $\begin{array}{c}0.01153 \\
75\end{array}$ & 17.50 & $\begin{array}{c}6.59 \times 1 \\
0-4\end{array}$ & 209.83 & 0.28 \\
\hline
\end{tabular}

From the above table, it has been found that the cavitation number varies with respect to inlet pressure. This infers, the cavitation number decreases with increase in the inlet pressure additionally the flow rate of liquid passing through the main line .It is also found that the low cavitation number favours the dye degradation.

The maximum numbers of cavities are formed at cavitation number less than or equal to 1 . It may be greater than 1 as well when suspended solids and dissolved gases exist in the wastewater [33].
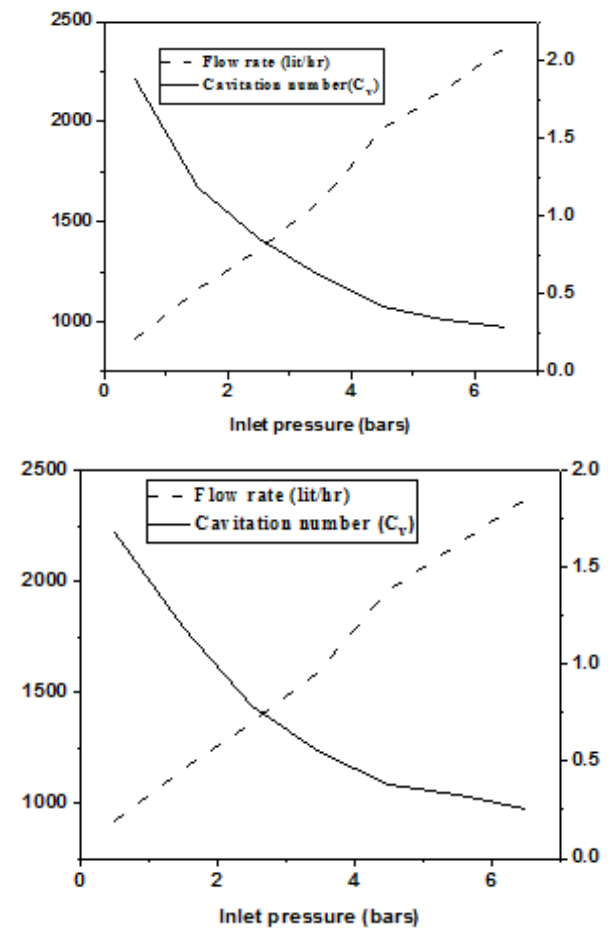

Fig. 3: Flow rate and $\mathrm{CV}$ plots in reference with inlet pressure for circular and hexagonal holes orifice plates

The following table provides the data which is associated with the flow rate and cavitation numbers at different inlet pressures.

Table 2: Cavitation number calculations for orifice plate with 8no.of hexagonal holes

\begin{tabular}{|c|c|c|c|c|c|}
\hline $\begin{array}{c}\text { Pressu } \\
\text { re } \\
\text { (bars) }\end{array}$ & $\begin{array}{c}\text { Volume } \\
\text { Collecte } \\
\mathbf{d} \\
(\mathbf{m 3})\end{array}$ & $\begin{array}{c}\text { Time } \\
\text { taken } \\
\text { for } \\
\text { collecti } \\
\text { on (s) }\end{array}$ & $\begin{array}{c}\text { Flow } \\
\text { rate } \\
(\mathbf{m 3} / \mathbf{s}) \\
(\mathbf{Q})\end{array}$ & $\begin{array}{c}\text { Velocity } \\
\mathbf{a t} \\
\text { Orifice( } \\
\text { Vo) (m/s) }\end{array}$ & $\mathbf{C v}$ \\
\hline 0.5 & $\begin{array}{c}0.01153 \\
75\end{array}$ & 42.65 & $\begin{array}{c}2.705 \times 1 \\
0-4\end{array}$ & 86.107 & $\begin{array}{c}1.67 \\
6\end{array}$ \\
\hline 1.5 & $\begin{array}{c}0.01153 \\
75\end{array}$ & 34.38 & $\begin{array}{c}3.35 \times 10 \\
-4\end{array}$ & 106.82 & $\begin{array}{c}1.08 \\
9\end{array}$ \\
\hline 2.5 & $\begin{array}{c}0.01153 \\
75\end{array}$ & 29.18 & $\begin{array}{c}3.95 \times 10 \\
-4\end{array}$ & 125.81 & $\begin{array}{c}0.78 \\
5\end{array}$ \\
\hline 3.5 & $\begin{array}{c}0.01153 \\
75\end{array}$ & 24.29 & $\begin{array}{c}4.74 \times 10 \\
-4\end{array}$ & 151.13 & $\begin{array}{c}0.54 \\
4\end{array}$ \\
\hline 4.5 & $\begin{array}{c}0.01153 \\
75\end{array}$ & 20.17 & $\begin{array}{c}5.71 \times 10 \\
-4\end{array}$ & 182.03 & $\begin{array}{c}0.37 \\
5\end{array}$ \\
\hline 5.5 & $\begin{array}{c}0.01153 \\
75\end{array}$ & 18.78 & $\begin{array}{c}6.14 \times 10 \\
-4\end{array}$ & 195.53 & 0.32 \\
5
\end{tabular}

With further decrease in the cavitation number below 0.15 , the rate of dye degradation decreases correspondingly. When this situation occurs, the cavitation chamber gets occupied with large number of cavities (choked cavitation) which causes cavitation cloud at downstream region of the orifice.

These massive bubbles move proactively along the flow without getting completely collapsed or partially collapsed, thus reducing the cavitational yield which thereby reduces generation of $\mathrm{OH}^{*}$ radicals.

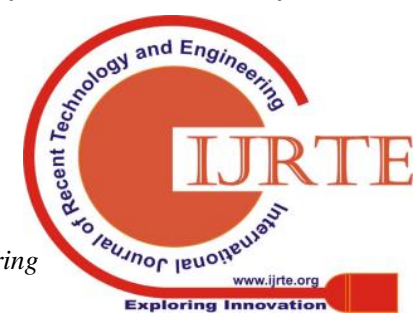




\section{DEGRADATION OF AZODYES IN WASTEWATER BY USING HYDRODYNAMIC CAVITATION TECHNIQUE}

\section{Effect of Inlet Pressure on Dye Degradation}

Orifice inlet pressure affects cavitational phenomena inside the cavitating device (Hydrodynamic cavitation device). The intensity of cavitation (magnitude of collapse pressure) and density of cavities being delivered relies majorly on the inlet pressure.

From the figure 4.3,it is observed that the dye degradation efficiency increases with decrease of absorption rate. Experiments are conducted at different inlet pressures ranging from 3 to 6 bars at $60 \mathrm{~min}$ time of operation and the results are plotted in the figure 4.4. The plot shows that, the degradation efficiencies were around $17.2 \%, 24.7 \%, 46.27 \%$ and $48.33 \%$ at inlet pressuresof $3,4,5$ and 6 bars respectively.

As the degradation efficiencies at 5 and 6 bars are almost same, the degradation efficiency at 5 bars (i.e.46.27\%) is considered for further analysis. When the cavitating device reaches optimum inlet pressure, huge number of cavities develops which is called as choked cavitation. This is not recommended for dye degradation.
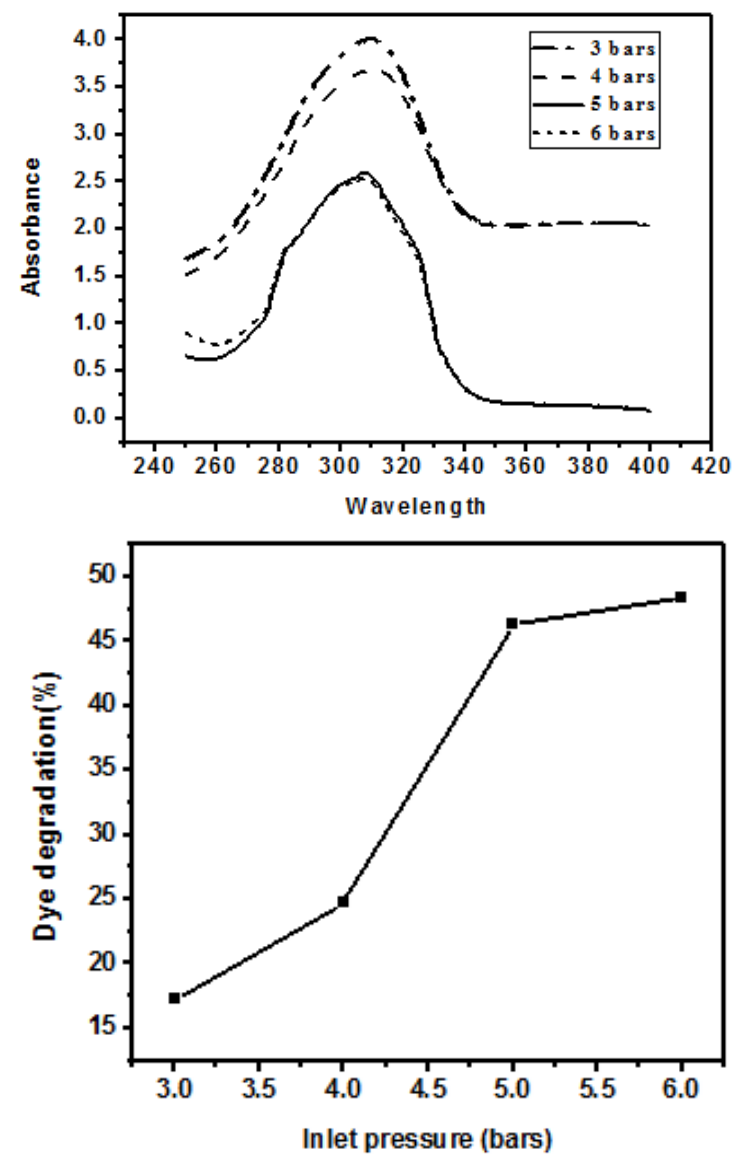

Fig.4: The plots in the figure correspond to values of absorbance of the methyl blue dye at 3 bars (dash dotted line), 4 bars (broken line), 5bars (solid line) and at 6bars (dotted line) at 60 mins of time of operationwith circular hole (8 No.) orifice geometry, initial conc. $40 \mathrm{mg} / \mathrm{l}$ and pH 7
Effect of Orifice Geometry and Oxidizing agent on Dye Degradation

Orifice Plate with Circular Holes (8 No.) with \& without $\mathrm{H}_{2} \mathrm{O}_{2}$

The UV peaks in the figure 4.5 shows that Methyl blue degradation with and without $\mathrm{H}_{2} \mathrm{O}_{2}$ addition for an orifice plate with 8 number of circular holes. Hydrodynamic cavitation (HC) combined with concentrated $\mathrm{H}_{2} \mathrm{O}_{2}$ plays a significant role in the degradation of dyes. Under ideal cavitational conditions, this technique effectively affects the decolorization process. Because of its high oxidation limit $(1.78 \mathrm{eV}), \mathrm{H}_{2} \mathrm{O}_{2}$ easily decomposes into more number of $\mathrm{OH}^{*}$ radicals. With $\mathrm{H}_{2} \mathrm{O}_{2}$, the absorbance value is less compared to without $\mathrm{H}_{2} \mathrm{O}_{2}$.

It implies that, maximum dye degradation is observed at low absorbance value. At $30 \mathrm{~min}$ time of operation, without $\mathrm{H}_{2} \mathrm{O}_{2}$ the methyl blue dye degradation is around $20-22 \%$.

When $\mathrm{H}_{2} \mathrm{O}_{2}$ is added to the dye wastewater, the rate of degradation is observed as $30-35 \%$. It implies that, the degradation efficiency is $10-15 \%$ more as compared with orifice plate of circular holes without $\mathrm{H}_{2} \mathrm{O}_{2}$.

It is due to increase in the generation of $\mathrm{OH}^{*}$ radicals. This shows that the oxidizing agent plays a significant role in enhanced dye degradation.

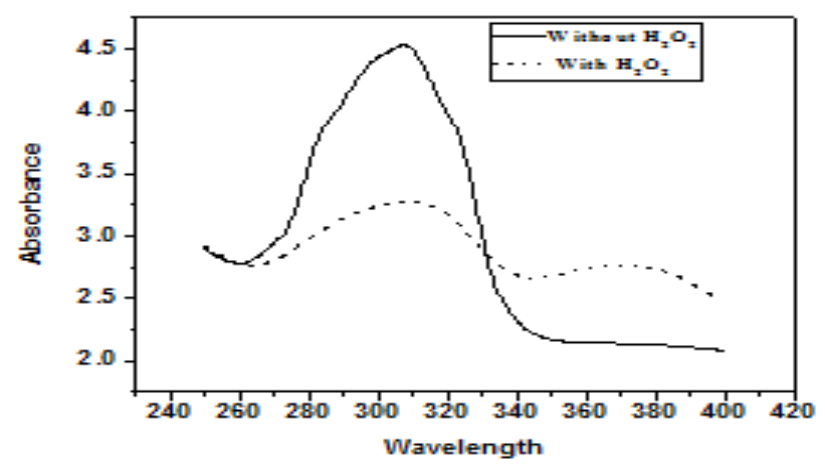

Fig. 5: The plots in the figure correspond to values of absorbance of the methyl blue dye without $\mathrm{H} 2 \mathrm{O} 2$ at 30 min (Solid Line) and with $\mathrm{H} 2 \mathrm{O} 2$ at $30 \mathrm{~min}$ (dotted line) of time of operation with circular hole $(8 \mathrm{No}$.) orifice geometry. The operating pressure is 5 bar, initial conc. $40 \mathrm{mg} / \mathrm{l}$ and $\mathrm{pH} 7$

Orifice Plate with Hexagonal Holes (8No.) with \& without $\mathrm{H}_{2} \mathrm{O}_{2}$

The UV peaks in the figure 4.10 shows that Methyl blue degradation with and without $\mathrm{H}_{2} \mathrm{O}_{2}$ addition for an orifice plate with 8 no. of hexagonal holes. At $30 \mathrm{~min}$ time of operation, without $\mathrm{H}_{2} \mathrm{O}_{2}$ the observed degradation efficiency for methyl blue is around $20-30 \%$.

When $\mathrm{H}_{2} \mathrm{O}_{2}$ is added to the dye wastewater the rate of degradation is observed as $45-50 \%$. It implies that, the degradation efficiency is $15-20 \%$ more as compared with orifice plate consist hexagonal holes without $\mathrm{H}_{2} \mathrm{O}_{2}$.

It is due to releases huge number of $\mathrm{OH}^{*}$ radicals by adding $\mathrm{H}_{2} \mathrm{O}_{2}$. One more reason behind good degradation is that the flow turbulence. 
The flow turbulence increases with hexagonal holes of orifice plate which in turn increases the cavity collapse phenomenon and releases huge amount cavitational energy at downstream region of orifice.

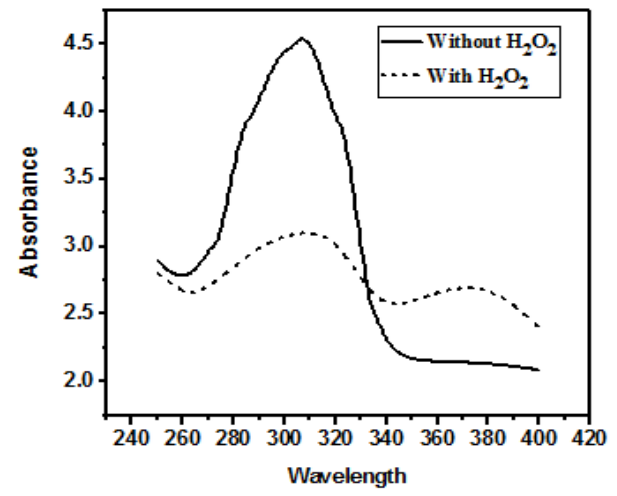

Fig. 6: The plots in the figure correspond to values of absorbance of the methyl blue dye with h2o2 at $30 \mathrm{~min}$ (solid line) and without $\mathrm{H} 2 \mathrm{O2}$ at $30 \mathrm{~min}$ (dotted line) of time of operation with hexagonal hole ( 8 No.) orifice geometry. The operating pressure is 5 bar, initial conc. $40 \mathrm{mg} / \mathrm{l}$ and ph 7

Comparison of Circular \&Hexagonal Holes (8No.) of Orifice Plate without $\mathrm{H}_{2} \mathrm{O}_{2}$

From the figure 3 it is observed that, the Methyl blue dye degradation for orifice plate with hexagonal openings is 5$10 \%$ more (approx.) when compared with orifice plate with circular openings. It is due to generation of more number of $\mathrm{OH}^{*}$ radicals and high collapsing pressure at downstream region of orifice plate. The collapsed pressure depends on flow turbulence and the flow turbulence increases by using orifice plate with hexagonal holes.

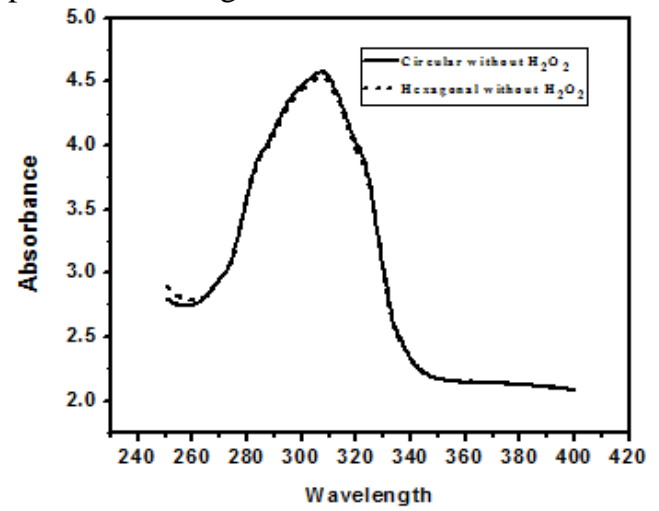

Fig.7: The plots in the figure correspond to values of absorbance of the methyl blue dye without $\mathrm{H2O} 2$ at 30 min (solid line, dotted line) of time of operation withcircular \& hexagonal hole $(8$ no.) orifice geometry. The operating inlet pressure is 5 bar, initial conc. of 40 $\mathrm{mg} / \mathrm{l}$ and $\mathrm{pH}$ of 7

Comparison of Circular \&Hexagonal Holes (8No.) of Orifice Plate with $\mathrm{H}_{2} \mathrm{O}_{2}$

The rate of dye degradation is studied by conducting experiments at a molar ratio of 1:40 (dye conc. to hydrogen peroxide conc.) to determine the overall efficiency of degradation process. The rateof degradation is observed by using UV absorption peaks as shown in figure 4.8. From the figure 4.9 it is concluded that, at 30 mins time of operation the degradation efficiency is around $10-15 \%$ high when compared with orifice plate with circular holes, it is due to releases large number of $\mathrm{OH}^{*}$ radicals and also due to high flow turbulence.

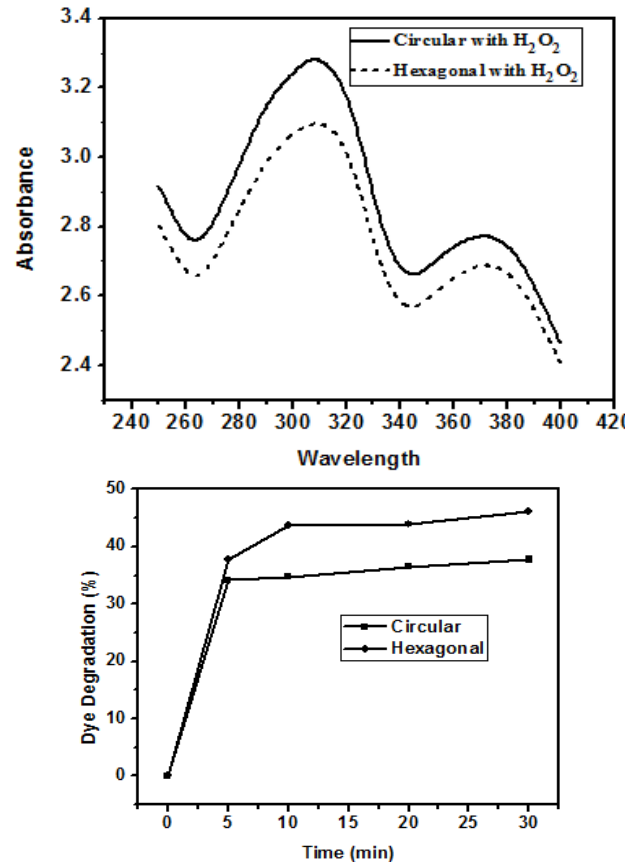

Fig.8: The plots in the figure correspond to values of absorbance of the methyl blue dye with $\mathrm{H2O2}$ at 30 min

(solid line) and at $30 \mathrm{~min}$ (dotted line) of time of operation with circular \& hexagonal hole ( 8 no.) orifice geometry. The operating pressure is 5 bar, initial conc. $40 \mathrm{mg} / \mathrm{l}$ and ph 7

\section{CONCLUSIONS}

The following conclusions were drawn for methyl blue dye by using hydrodynamic cavitation technique

- Low cavitation number (i.e, $\leq 1$ ) is favourable for good dye degradation. From the experimental data it should be concluded that the cavitation number is less for orifice plate with hexagonal holes (8 No.) compared with orifice plate with circular holes $(8$ No.).

- Maximum dye degradation is observed at an inlet pressure of 5 bars among different inlet pressures (3, 4, 5 and 6 bars)

- At an optimum inlet pressure of 5 bars and at $\mathrm{pH} 7$ with Hydrodynamic cavitation (without $\mathrm{H}_{2} \mathrm{O}_{2}$ ) the degradation efficiency for orifice plate with both circular and hexagonal holes (8 no.) is approximately same.

- At an optimum inlet pressure of 5 bars and at $\mathrm{pH} 7$ Hydrodynamic cavitation with $\mathrm{H}_{2} \mathrm{O}_{2}$ the percentage of dye degradation is $10-15 \%$ more for orifice plate with hexagonal holes ( 8 no.) compared with orifice plate with circular holes ( 8 no.). 


\section{DEGRADATION OF AZODYES IN WASTEWATER BY USING HYDRODYNAMIC CAVITATION TECHNIQUE}

\section{REFERENCES}

1. De Gisi, Sabino, Giusy Lofrano, Mariangela Grassi, and Michele Notarnicola. 2016. "Characteristics and Adsorption Capacities of Low-Cost Sorbents For Wastewater Treatment: A Review". Sustainable Materials and Technologies 9: 10-40.

2. Mojsov, Kiro D., Darko Andronikov, Aco Janevski, Aco Kuzelov, and Steven Gaber. 2016. "The Application Of Enzymes For The Removal Of Dyes From Textile Effluents". Advanced Technologies 5 (1): 81-86.

3. Liu, Lixia, Juan Zhang, Yi Tan, Yucheng Jiang, Mancheng Hu, Shuni Li, and Quanguo Zhai. 2014. "Rapid Decolorization Of Anthraquinone And Triphenylmethane Dye Using Chloroperoxidase: Catalytic Mechanism, Analysis Of Products And Degradation Route". Chemical Engineering Journal 244: 9-18.

4. Al-Alwani, Mahmoud A.M., Norasikin A. Ludin, Abu Bakar Mohamad, Abd. Amir H. Kadhum, and Abduljabbar Mukhlus. 2018. "Application Of Dyes Extracted From Alternanthera Dentata Leaves And Musa Acuminata Bracts As Natural Sensitizers For DyeSensitized Solar Cells". Spectrochimica Acta Part A: Molecular and Biomolecular Spectroscopy 192: 487-498.

5. Rodríguez-Couto, Susana, Johann Faccelo Osma, and José Luis Toca-Herrera. 2009. "Removal Of Synthetic Dyes By An Eco-Friendly Strategy". Engineering In Life Sciences 9 (2): 116-123.

6. Rajoriya, Sunil, et al. "Hydrodynamic cavitation: an advanced oxidation process for the degradation of biorefractory pollutants." Reviews in Chemical engg. 32.4 (2016): 379-411.

7. V.K. Saharan, A.B. Pandit, P.S. SatishKumar, S. Anandan, Hydrodynamic cavitation as an advanced oxidation technique for the degradation of Acid Red 88 dye, Ind. Eng. Chem. Res. (2011),

8. Wang X, Wang J, Guo P, Guo W, Wang C. Degradation of Rhodamine $\mathrm{B}$ in aqueous solution by using swirling jet-induced cavitation combined with $\mathrm{H}_{2} \mathrm{O}_{2}$. J Hazard Mater 2009; 169: 486-491.

9. Wang J, Wang X, Guo P, Yu J. Degradation of reactive brilliant red $\mathrm{K}-2 \mathrm{BP}$ in aqueous solution using swirling jet-induced cavitation combined with $\mathrm{H}_{2} \mathrm{O}_{2}$. Ultrason Sonochem 2011b; 18: 494-500.

10. Ed Zwaan, Severine Le Gac, Kinko Tsuji, and ClausDieter Oh controlled cavitation in micro fluidics, physical review letters.

11. V.K.Saharan,Mandar P.Badve,A.B.Pandit,Degradation of Reactive Red 120 dye using Hydrodynamic cavitation, chemical engg. 178(2011)100-107.

12. A.A.Pradhan,P.R.Gogate,Chem.Eng.J.2010,156(1),77082.

13. K.P.Mishra,P.R.Gogate,Sep.Purif.Technol.2010,75(3), 385-391.

14. M.M.Goreetal,Ultrason.Sonochem.2014,21(3),1075-082.

15. M.V.Bagal,P.R.Gogate,Ultra.Sonochem.2014,21(3),1035 $-1043$.

16. P.N.Patil et al., Ultrason. Sonochem. 2014, 21 (5), 17701777.

17. Mishra KP, Gogate PR. Intensification of degradation of Rhodamine B using hydrodynamic cavitation in the presence of additives. Sep Purif Technol 2010; 75: 385391

18. Wu Y, Huang Y, Zhou Y, Ren X, Yang F. Degradation of chitosan by swirling cavitation. Innov Food Sci Emerg Technol 2014; 23: 188-193.

19. Braeutigam P, Franke M, Schneider RJ, Lehmann A, Stolle A, Ondruschka B. Degradation of carbamazepine in environmentally relevant concentrations in water by hydrodynamic-acoustic cavitation (HAC). Water Res 2012; 46: 2469-2477.

20. Adewuyi, Y. G. Sonochemistry: Environmental science and engineering applications. Ind. Eng. Chem. Res. 2001, 40, 4681.

21. Lorimer, J. P.; Manson, T. J. Sonochemistry: Part 1_The physical aspects. Chem. Soc. Rev. 1987, 16, 239.

22. Anandan, S.; Lee, G.; Chen, P.; Fan, C.; Wu, J. J. Removal of orange II dye in water by visible lightassisted photocatalytic ozonation using $\mathrm{Bi} 2 \mathrm{O} 3$ and Au/Bi2O3 nanorods. Ind. Eng. Chem. Res. 2010, 49, 9729

23. ]Bigda, R.J.Fenton's chemistry:An effective advanced oxidation process.Environ.Technol.1996, 6, 34.

24. Didenko, Yuri T., William B. McNamara, and Kenneth S. Suslick. "Hot spot conditions during cavitation in water." Journal of the American Chemical Society 121.24 (1999): 5817-5818.

25. Echigo, S.; Yamada, H.; Matsui, S.; Kawanishi, S.; Shishida, K. Comparison between O3/VUV, $\mathrm{O} 3 / \mathrm{H}_{2} \mathrm{O}_{2}$, $\mathrm{UV}$ and $\mathrm{O} 3$ processes for the decomposition of organophosphoric acid trimesters. Water Sci. Technol. 1996, 34, 81.

26. Hoffmann, M. R.; Hua, I.; Hochemer, R. Application of ultrasonic irradiation for the degradation of chemical contaminants in water. Ultrason. Sonochem. 1996, 3, 163.

27. Nagata, Y.; Nakagawa, M.; Okuno, H.; Mizukoshi, Y.; Yim, B.; Maeda, Y. Sonochemical degradation of chlorophenols in water. Ultrason. Sonochem. 2000, 7, 115.

28. Weavers, L. K.; Ling, F. H.; Hoffmann, M. R. Aromatic compound degradation in water using a combination of sonolysis and ozonolysis. Environ. Sci. Technol. 1998, 32,2727

29. Kang, J. W.; Hoffmann, M. R. Kinetic and mechanism of the sonolytic destruction of methyl tert-butyl ether by ultrasonic irradiation in the presence of ozone. Environ. Sci. Technol. 1998, 32, 3194

30. Papić, Sanja, et al. "Decolourization and mineralization of commercial reactive dyes by using homogeneous and heterogeneous Fenton and UV/Fenton processes." Journal of Hazardous Materials 164.2-3 (2009): 1137-1145.

31. Lai Fatt Chuah, Abdul Rashid Abd Aziz, Suzana Yusup, Awais Bokhari, Jiří Jaromír Klemeš, Mohd Zamri Abdullah "Performance and emission of diesel engine fuelled by waste cooking oil methyl ester derived from palm olein using hydrodynamic cavitation" Clean Technologies and Environmental Policy, December 2015, Volume 17, Issue 8, pp 2229-2241.

32. Saumaya Kirti, Vinay M. Bhandari, Jyotsnarani Jena, Laxmi Gayatri Sorokhaibam,Arnab S. Bhattacharyya "Exploiting functionalities of biomass in nanocomposite development: application in dye removal and disinfection along with process intensification" Clean Technologies and Environmental Policy, July 2018, Volume 20, Issue 5, pp 981-994. 